\title{
Consequences of spawning at low tide: limited gamete dispersal for a rockpool anemone
}

\author{
Dustin J. Marshall ${ }^{1,2, *}$, David Semmens ${ }^{1}$, Carly Cook $^{1}$ \\ ${ }^{1}$ Department of Zoology, The University of Melbourne, Victoria 3010, Australia \\ ${ }^{2}$ Present address: School of Biological, Earth and Environmental Sciences, The University of New South Wales, \\ Sydney 2052, Australia
}

\begin{abstract}
Recently, there has been much debate surrounding the importance of sperm limitation to the population dynamics and evolution of life-history traits of free-spawning marine invertebrates. The debate is hampered by a lack of measures of fertilisation success from natural spawning events. We observed the natural spawning of the intertidal anemone Oulactis mucosa during a low tide in SE Australia. The fertilisation success of individual females was assessed, as well as the degree of spawning synchrony among and within rockpools. We found that fertilisation success was extremely variable among females; females spawning in rockpools containing spawning males had much higher fertilisation success than females in pools without males. Spawned gametes remained in a viscous matrix throughout the low tide, and the movement of sperm among pools appeared to be minimal. Consequently, isolated females had very low rates of fertilisation success, and spawning synchrony in all-female pools strongly depended on the distance to the nearest neighbouring pool containing a spawning male. We suggest that spawning at low tide may minimise the problems associated with gamete dilution, but also results in poor communication among spawning individuals and thus limited genetic exchange at reproduction and low rates of synchrony.
\end{abstract}

KEY WORDS: Broadcast spawner $\cdot$ Reproductive success $\cdot$ Chemical communication

\section{INTRODUCTION}

Reproducing by freely spawning eggs and sperm into the water column was thought to result in the vast majority of eggs being fertilised (Thorson 1950). This view changed when manipulative field experiments on echinoids showed that spawned sperm can quickly become diluted, resulting in very low fertilisation rates of eggs when females and males were separated by relatively small distances (Pennington 1985). Subsequent experiments led to the suggestion that unless free-spawners were at very high densities, fertilisation success could be so low that populations might be limited by sperm availability (Levitan 1995, Levitan \& Petersen 1995). Furthermore, it was suggested that the effects of egg size on fertilisation dynamics might drive the evolution of egg size in free-spawners (Levitan 1993, 2000). Given its potential importance, the num- ber of fertilisation studies increased rapidly in the 1990s, and many suggested that reproduction in these species could be sperm-limited (reviewed by Levitan 1995 and Yund 2000).

Field experiments have demonstrated that fertilisation success can be very low (reviewed by Levitan 1995), but many species do not fit the sperm-limitation model (Yund 2000). Some naturally spawning populations show relatively high levels of fertilisation success (reviewed by Yund 2000). Brooding invertebrates (those that broadcast sperm but not eggs) and fucoid algae often show high rates of fertilisation in the field (Serrao et al. 1996, Temkin 1996, Brawley et al. 1999, Berndt et al. 2002). Yund (2000) suggested that previous manipulative experiments may have underestimated probable fertilisation rates in the field because they bypassed natural spawning behaviours that enhance fertilisation success. Recent experiments have 
suggested that spawned eggs may not disperse very far and can remain viable for longer than previously expected (Meidel \& Yund 2001, Yund \& Meidel 2003). Earlier experiments may therefore have underestimated natural fertilisation success because they did not run long enough (Yund \& Meidel 2003).

More broadly, the relevance of manipulative experiments is hard to assess in the absence of knowledge about natural spawnings. For example, although spawning synchrony is often assumed to be high (Denny \& Shibata 1989, Yund \& McCartney 1994, Clareboudt 1999), there is very little support for this crucial assumption and, in some cases, natural spawning can be remarkably asynchronous (Levitan 1988, Marshall 2002). This assumption is crucial, because it is used to link population density to effective spawner density. For example, if natural spawning is asynchronous but all individuals are induced to spawn (e.g. Franke et al. 2003), then sperm concentrations will be overestimated. Similarly, experiments where spawned gametes are retained artificially may overestimate fertilisation success if natural gamete retention times are very short (e.g. Marshall 2002).

To gain a better understanding of natural fertilisation rates in the field, more observations of natural spawning are imperative. Observations of natural spawnings provide more than mere estimates of natural fertilisation success. Such observations also allow us to effectively link the results of manipulative studies to natural situations by providing estimates of spawning synchrony, natural spawning behaviour and gamete retention times (e.g. Marshall 2002, Styan \& Butler 2003). Such observations are difficult to make because of the unpredictability of most natural spawnings and, subsequently, data are extremely scarce for most habitats.

One habitat in which a number of natural spawnings have been observed is the rocky intertidal. This habitat remains one of the most interesting in which to study fertilisation for a number of reasons. Hydrodynamic conditions are extremely variable and fertilisation success is predicted to be relatively low (Denny \& Shibata 1989, Mead \& Denny 1995, but see Denny et al. 2002). However, observations of natural spawnings of several algal species and an intertidal ascidian during low tides have shown that free-spawning can be relatively successful in this harsh habitat. Moreover, recent experiments have suggested that too many sperm, rather than too few, may limit fertilisation success within rockpools because sperm dilution is very low (Franke et al. 2003). Nevertheless, it has been suggested that whilst spawning at low tide reduces gamete dilution, it may also reduce the ability of individuals within a population to spawn synchronously (Marshall 2002). Clearly, more observations of intertidal spawnings are needed to further resolve these issues.
Sea anemones are a fascinating group of intertidal organisms, and have not had their natural spawning observed in detail. Anemones as a group are interesting from a fertilisation ecology perspective for a number of reasons. First, many anemone species reproduce both sexually and asexually via cloning, and this can result in locally biased sex ratios, with patches of all males and patches of all females (Chia 1976, Shick 1976, Sebens 1981, Ayre 1988, Billingham \& Ayre 1997). It has been suggested that reproduction by freespawning may therefore be problematic because of the large distances between males and females (Sebens 1981), but this remains to be tested. Second, many species of anemones spawn in response to the presence of sperm (Spaulding 1972, Clark \& Dewell 1974), and it is thought that males signal females to spawn in this way. Given that anemones have been reported to spawn at low tide or during periods of emersion (Siebert 1974, Sebens 1981, Strathmann 1991), spawning synchrony may be relatively low because of a lack of communication between individuals (e.g. Marshall 2002). Third, a number of anemone species exhibit remarkable spawning behaviour, moving to reduce the distance between males and females, and even displaying a form of pseudocopulation (Nyholm 1943, 1949: in Shick 1991), suggesting that sperm limitation could otherwise be a problem. Finally, clonal anemones typically have very low rates of sexually derived recruitment (Shick 1991, but see Sebens 1981), which may be due to very low fertilisation rates.

We observed the natural spawning of the intertidal anemone Oulactis mucosa during a low tide in the rocky intertidal zone of a reef in southern Australia. We measured female fertilisation success and how success varied with the presence and distance to the nearest spawning male. We also measured spawning synchrony within and among rockpools, the sex ratio of spawners, and gamete retention times. Not all individuals spawned, and we found highly skewed sex ratios of spawners within rockpools. We therefore returned to the reef on a second occasion, 5 mo later, and determined the overall sex ratio of all the individuals within pools.

\section{MATERIALS AND METHODS}

Study site and organism. The study site is a moderately exposed, sandstone, intertidal reef $(80 \times 20 \mathrm{~m})$ located near The Bluff, Barwon Heads, Victoria, in SE Australia. Spawning was observed on only 1 section of the reef at low tide; individuals further along the reef did not spawn during our observation period. At The Bluff, Oulactis mucosa occurs mainly in the upper intertidal zone, and the majority of individuals are 
submerged in small ( $200 \mathrm{~mm}$ wide, $\sim 80 \mathrm{~mm}$ deep) rockpools and fissures during low tide. Within rockpools, densities of individuals are typically fairly low $\left(\sim 3 \mathrm{~m}^{-2}\right)$. Throughout low tide, there is only very occasional wave swash through this upper zone, and during high tide this zone is completely submerged and is usually battered by high-energy waves.

Fertilisation success. Because spawned eggs remained around the individual females, we were able to assess their individual fertilisation success. We were interested in the relationship between the individual fertilisation success of females and the presence of/distance to the nearest spawning male. At the time of egg collection, we recorded the size of the rockpool and the number and proximity of spawning males within each female's rockpool. For rockpools with no spawning males present, we measured the distance to the nearest neighbouring rockpool containing a spawning male. We collected small samples ( 1000) of eggs of haphazardly selected individuals using clean, plastic spatulas. The eggs were placed in individual zip-lock bags, and $\sim 100 \mathrm{ml}$ of seawater was added. The eggs were then left to incubate in the zip-lock bags for $4 \mathrm{~h}$, by which time they had reached the 16 to 32 -cell stage. We then assessed fertilisation success by examining 60 randomly selected eggs under a dissecting $(40 \times$ power) microscope. Eggs were classed as 'fertilised' if they showed normal cleavage patterns.

We hypothesised that spawning females in rockpools containing no spawning males and isolated from other pools would have relatively low fertilisation success due to sperm limitation. To test this hypothesis, we examined how the experimental addition of extra sperm affected the fertilisation success of these isolated females. We collected eggs from isolated females $(n=3)$ and placed them in zip-lock bags. We then left half of the eggs to incubate as described above, and exposed the other half to a freshly collected batch of sperm. We then left the eggs to develop and estimated fertilisation success as described above. Ideally, we should have sampled the eggs at the end of a full tidal cycle, however the incoming tide quickly washed away any eggs, making further sampling impossible.

The incoming tide inundated the rockpools, and the gametes of Oulactis mucosa were quickly washed away (see 'Results'), but some pools higher on the shore were inundated more slowly. We hypothesised that because the eggs of females within the higher rockpools were exposed to sperm for a longer period, their fertilisation success might increase during a low tide. To test this, we compared the fertilisation success of high-shore females during and after low tide (when the gametes in the lower rockpools had been washed away). We first sampled the eggs of the high-shore females at the same time as the other rockpools and then again $2 \mathrm{~h}$ later.
Spawning synchrony. We observed spawning of Oulactis mucosa throughout a single low tide, examining every individual we could find on an approximately $120 \mathrm{~m}^{2}$ section of reef. Throughout the tidal period, we recorded the number of individuals that had and had not spawned. When O. mucosa spawned, the majority of gametes remained as a viscous matrix on top of and around the individual spawners (see 'Results') throughout the low-tide period, we therefore did not have to actually observe spawning in order to class an individual as 'spawned'. We counted the number of individuals that had or had not spawned within individual rockpools and also classified the spawned individuals as male or female. O. mucosa is dioecious (Hunt \& Ayre 1989), and gametes are easily distinguished, as spawned eggs are dark grey and the sperm creamy white. To determine whether spawning synchrony was affected by the proximity of other pools containing spawning males, we also measured the distance to the nearest neighbouring rockpool containing a spawning male (distance from outer edge of one pool to the other).

Sex ratios. It became apparent that the sex ratio of spawning individuals was highly skewed within rockpools, with most rockpools containing only 1 sex spawning (see 'Results - Spawning synchrony'). To determine whether this reflected an overall bias in sex ratios within pools, we returned to the site 5 mo after the spawning event to examine overall sex ratios. An interim period between spawning and resampling was necessary to allow the gonads to reach a size thas was large enough for sex determination by dissection (Hunt \& Ayre 1989). We haphazardly selected 16 rockpools, and mapped and sexed anemones within those pools. We could not collect and sex some (4 of 42 ) anemones as they could not be removed without crushing the individual, thus making sexing impossible.

Data analysis. To examine the effect of the presence/absence of spawning males on female fertilisation success, we compared the fertilisation success of females in rockpools with and without spawning males using ANOVA. In rockpools that contained more than 1 spawning female, we randomly selected 1 female from each rockpool to be examined. For females that did not have spawning males in their rockpool, we also examined the effect of proximity to the nearest neighbouring pool containing a spawning male on female fertilisation success using linear regression. We also used linear regression to analyse the effect of male densities within pools on female fertilisation success.

For analyses of the synchrony of spawning anemones within rockpools, we only analysed data from rockpools containing more than 1 anemone. We used ANCOVA to examine the effect of the presence of spawning males within pools and the distance to the 
nearest neighbouring pool containing a spawning male. Male presence/absence was a categorical variable, distance to the nearest neighbouring pool containing a spawning male was the covariate, and the proportion of anemones spawning within a pool was the response variable. The data met most of the assumptions required for ANOVA, but the data were slightly skewed. Arcsine square-root transformation did not improve the distribution of the data, nor did it improve the fit of the models or outcomes of the statistical models, and so results using raw data are presented here.

\section{RESULTS}

\section{General observations}

Spawning of Oulactis mucosa in rock pools was observed during the low, afternoon tide of 15 December 2002 . The day was sunny $\left(\sim 32^{\circ} \mathrm{C}\right)$, with little or no wind and calm seas; the sea-surface temperature at this time was $\sim 18^{\circ} \mathrm{C}$. The low tide predicted for that day was at 14:32 h, a predicted height of $0.42 \mathrm{~m}$ above mean lower low water (MLLW) (National Tidal Facility, Flinders University). The moon phase was between the first quarter and full moon. Of the 67 anemones observed to spawn (of the 107 anemones on that section of the reef), 65 spawned in rockpools and 2 (1 male and 1 female) spawned whilst completely out of the water.

Both males and females were observed to spawn, and for both sexes the spawned gametes remained in a viscous matrix around the spawning individual. The gametes were released in a forceful expulsion, and dissection of spawned individuals $(n=5)$ showed that very few gametes (both eggs and sperm) remained in the gonad after spawning. The gametes remained in a very concentrated mass for the duration $(\sim 3 \mathrm{~h})$ of the low tide, but dispersed very quickly $(<1 \mathrm{~min})$ once the incoming tide submerged the rockpool. Fertilised eggs that were kept in the laboratory at $\sim 20^{\circ} \mathrm{C}$ developed into swimming planula larvae about $3 \mathrm{~d}$ after the spawning event. The planulae were large and variable in size (mean length $\times$ width $=20170 \mu^{2}{ }^{2}$, coefficient of variation $=15 \%$ ).

\section{Fertilisation success}

Individual female fertilisation success was extremely variable, ranging from 0 to $98 \%$. Mean fertilisation success for the population was $42 \%$. Females in rockpools with spawning males had much higher fertilisation success than females in pools without spawning males (ANOVA on untransformed data: $F_{1,22}=6.55$,

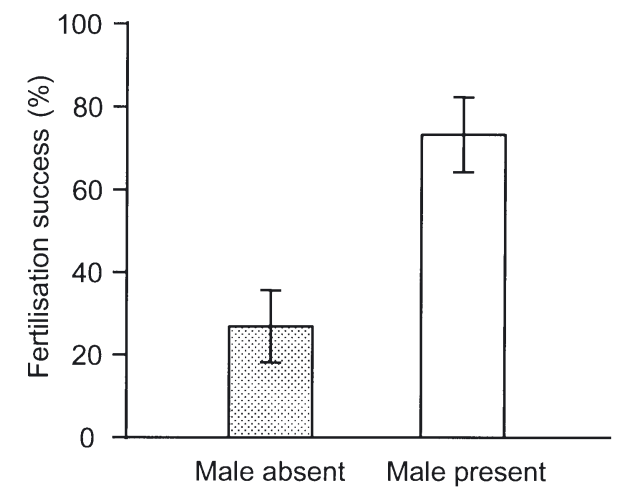

Fig. 1. Oulactis mucosa. Mean ( \pm SE) fertilisation success of females spawning in rockpools with and without spawning males at Barwon Heads, Australia

$\mathrm{p}=0.018 ;$ ANOVA on arcsine-transformed data: $F_{1,22}=6.22, \mathrm{p}=0.021$; Fig. 1). Within rockpools with both sexes spawning, female fertilisation success was not related to the density of males (no. of males/estimated area of pool) within pools $\left(\mathrm{n}=8, \mathrm{R}^{2}=0.003, \mathrm{p}=\right.$ 0.905 ) and was also unrelated to the distance to the nearest male $\left(n=8, R^{2}=0.08, p=0.495\right)$.

In rockpools without spawning males, female fertilisation success depended on the distance to the nearest rockpool containing a spawning male ( $\mathrm{n}=16$, $\mathrm{R}^{2}=0.607, \mathrm{p}<0.001$; Fig. 2). Fertilisation success was greatest for those females in rockpools that were relatively close to a rockpool containing a spawning male, and decreased sharply as the distance increased. Females that were $>90 \mathrm{~cm}$ away from the nearest rockpool containing a spawning male achieved very little $(<5 \%)$ fertilisation success. It should be noted, how-

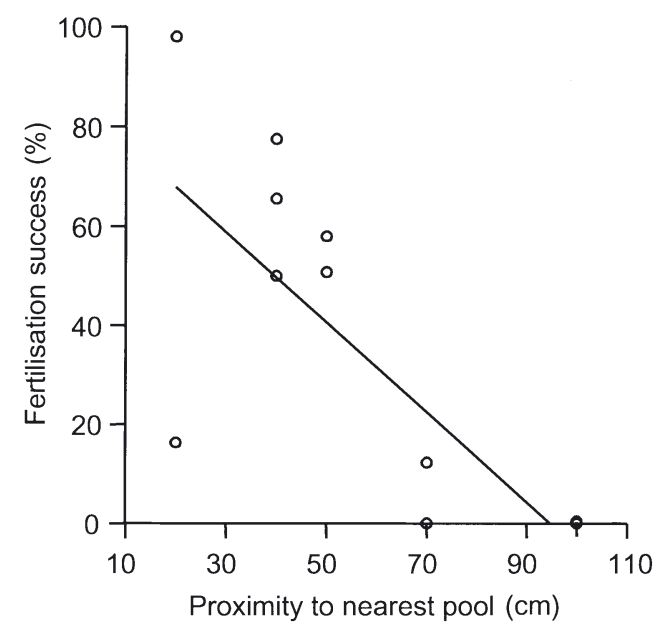

Fig. 2. Oulactis mucosa. Effect of distance to nearest rockpool containing spawning male on fertilisation success of females in all-female rockpools. Each data point represents fertilisation success of 1 female 
ever, that a nearby male was not a guarantee of high fertilisation success (Fig. 2). The low fertilisation success of these females was not due to low egg viability, because the experimental addition of sperm greatly increased the fertilisation rate of these eggs ( $\mathrm{n}=3$ broods, fertilisation success without added sperm = $0 \%$; average fertilisation success when sperm was added $=88.7 \%, \mathrm{SD}=11.1$ ).

The fertilisation success of isolated female Oulactis mucosa that were higher on the shore increased significantly over time (paired $t$-test: $t=3.58, \mathrm{df}=3$, $\mathrm{p}=0.037)$. The initial mean $( \pm \mathrm{SE})$ fertilisation success of females was $39.7 \pm 16 \%$, increasing to $69.2 \pm 12.8 \%$ after $2 \mathrm{~h}$.

\section{Spawning synchrony}

Of the 49 pools observed to contain anemones, 40 $(\sim 81 \%)$ contained 1 or more spawning individuals in them. In pools containing more than 1 anemone, the average $( \pm \mathrm{SE})$ proportion of anemones that had spawned was $61 \pm 6 \%$ (for rockpools with and without spawning males: Table 1). In rockpools without spawning males, the proportion of anemones that spawned (spawning synchrony) increased with proximity to the nearest pool containing a spawning male. In rockpools with spawning males present, spawning synchrony was variable and was unrelated to the nearest neighbouring pool containing a male (Table 1, Fig. 3).

Of the 67 anemones observed to spawn, 34 were males, giving a sex ratio of $\sim 1: 1$. Interestingly, the sex ratio appeared to be highly skewed within rockpools, with single-sex rockpools making up over $65 \%$ of all pools with $>1$ anemone spawning (Table 2).

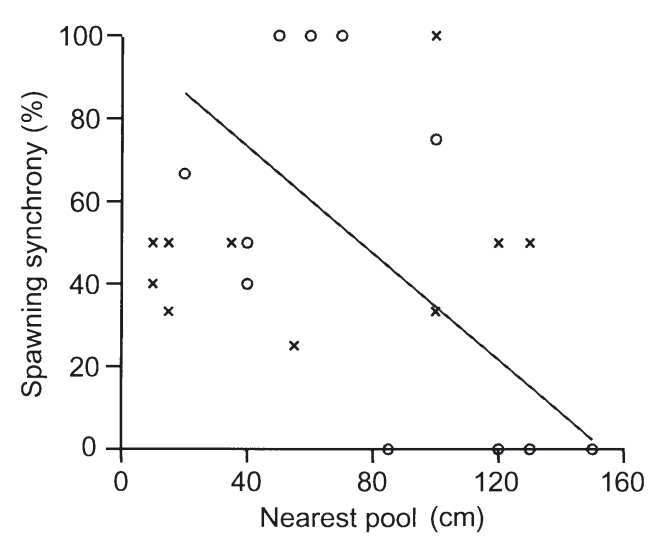

Fig. 3. Oulactis mucosa. Effect of distance to nearest rockpool containing spawning male on spawning synchrony in rockpools with $(x)$ and without (o) spawning males present. Each data point represents proportion of anemones spawning within a single rockpool
Table 1. Oulactis mucosa. ANCOVA comparing effect of spawning male presence/absence within a rockpool and distance to nearest neighbouring rockpool with a spawning male on spawning synchrony of within rockpools $(n=22)$ at Barwon Heads, Australia

\begin{tabular}{|lrccc|}
\hline Source & df & MS & $F$ & $\mathrm{p}$ \\
\hline Male presence & 1 & 0.497 & 5.412 & 0.032 \\
Distance & 1 & 0.197 & 2.161 & 0.159 \\
Male presence $\times$ Distance & 1 & 0.716 & 7.865 & 0.012 \\
Residual & 18 & 0.091 & & \\
\hline
\end{tabular}

Table 2. Oulactis mucosa. Number of rockpools containing only spawning males or spawning females

\begin{tabular}{|cccc|}
\hline $\begin{array}{c}\text { No. of spawning ane- } \\
\text { mones in rockpool }\end{array}$ & All male & Mixed & All female \\
\hline 2 & 4 & 2 & 6 \\
3 & 1 & 2 & \\
$>3$ & & 1 & \\
\hline
\end{tabular}

\section{Sex ratios}

The sex ratios of Oulactis mucosa within rockpools was still highly skewed 5 mo after the spawning event. In small rockpools (those with $<4$ anemones), individuals within pools were either entirely male or entirely female ( $\mathrm{n}=9$ pools, 19 anemones). Within larger pools, both sexes occurred but they appeared to be clumped, with separate aggregations of males and females.

\section{DISCUSSION}

Throughout the course of the low tide, the gametes of Oulactis mucosa remained in a viscous matrix on and around the individuals that spawned them. The spawning of gametes into a viscous matrix has now been observed in many free-spawning invertebrates (McEuen 1988, Thomas 1994a,b), including other species that spawn at low tide (Marshall 2002) and some anemone species (Siebert 1974, Schick \& Lamb 1977). By reducing the dispersal and dilution of gametes, spawning a viscous matrix probably enhances fertilisation through lengthening the viability of gametes and maintaining effective sperm concentrations (Thomas 1994a, Marshall 2002). A number of free-spawning intertidal species from a range of taxa have now been observed to spawn during low tide, and it is possible that spawning at low tide is a relatively widespread solution to the problems presented by this dynamic habitat (Sebens 1981, Strathmann 1991, Serrao et al. 1996, Williams et al. 1997, Brawley et al. 1999, Marshall 2002). However, other species spawn during 
times of low water movement rather than low tide per se (e.g. Berndt et al. 2002).

The fertilisation data we collected reflect the limited movement of most gametes among rockpools. Female fertilisation success depended strongly on the presence of spawning males within their rockpool. When males were present in rockpools, sperm concentrations were presumably higher and female fertilisation success was higher. When no spawning male was present, female fertilisation success depended on the distance to nearest rockpool containing a spawning male. The intermittent wave swash throughout the low tide may have transported some sperm among pools, but there must have been relatively little transportation, since distances greater than $1 \mathrm{~m}$ between pools typically resulted in no fertilisation success at all. In comparison, Pyura stolonifera achieves relatively higher fertilisation rates at similar separation distances when it spawns on the same reef (Marshall 2002). However, $P$. stolonifera occurs in a lower zone with more wave swash, and this may facilitate the movement of sperm among individuals.

Within rockpools containing spawning males, neither spawning male density nor distance to the nearest pool containing a spawning male affected fertilisation success. Franke et al. (2003) also found that male density had little effect on fertilisation success in the sea urchin Evechinus chloroticus induced to spawn in rockpools. It may be that within rockpools, occasional wave swash causes a high degree of mixing so that sperm concentrations are relatively uniform but very little sperm is washed between pools. This is analogous to the situation described by Denny et al. (1994), who found that within surge channels there was a high degree of internal mixing but only a small proportion of gametes moved among channels. Furthermore, Denny et al. (1994) noted that within small-volume channels, fertilisation success quickly plateaued, with small increases in the density of spawning males. This saturation effect may explain why we found no effect of the density of spawning males on fertilisation success. Alternatively, the increase in the density of spawning males and presumably sperm concentrations within pools may have resulted in an increase in the rate of polyspermy within pools, thereby counterbalancing the overall fertilisation rate (e.g. Brawley 1992, Franke et al. 2003).

Once the tide came in and waves began to flush the rockpools, the gametes were washed from the anemones and dispersed extremely quickly. The shore where spawning occurred is moderately exposed, with high turbulence and high shear stress (energy dissipation rates of ca. $>800 \mathrm{~W} \mathrm{~m}^{-3}$; T. Bolton \& D. Marshall unpubl. data). Consequently, once the eggs were washed from the surface of the anemones, very few would have been fertilised because of gamete dilution (Denny \& Shibata 1989, Mead \& Denny 1995, Denny et al. 2002). Therefore, the fertilisation rates recorded for eggs collected prior to the incoming tide are likely to provide a good estimate of fertilisation success, although they may slightly underestimate total success.

Meidel \& Yund (2001) suggest that instantaneous measures of fertilisation success may underestimate true fertilisation rates, and that time-integrated measures of fertilisation success are more representative. Our results support this suggestion, in that we found that fertilisation success increased over time for eggs that remained longer in the intertidal zone. Nevertheless, only individuals in the upper intertidal zone retained their spawned eggs longer, and such individuals were rare. For most individuals observed, spawned eggs were washed away within minutes after collection of our samples. This leads to an interesting speculation, i.e. that individuals in the upper intertidal zone may have lower growth rates and fecundity because they are immersed (and consequently feed) for shorter periods of time than conspecifics lower on the shore (Shick 1991). It appears that the upper intertidal individuals retain their eggs for longer and therefore have a greater opportunity to achieve high rates of fertilisation success independent of male presence/ absence, which may compensate for reduced fecundity.

For the vast majority of anemones observed spawning, the dispersal of gametes appeared to be highly restricted until the end of the low tide, after which little fertilisation is likely to occur. This has a number of important consequences.

First, the restricted dispersal of gametes means genetic exchange due to gamete dispersal is likely to be minimal (cf. Havenhand 1991). Many anemone species have been observed to have significant heterozygote deficiencies, even those in species that utilise sexual reproduction rather than asexual reproduction (Schick 1991, Edmands 1995). Hunt \& Ayre (1989) found low levels of genetic differentiation among local populations of Oulactis mucosa, and they suggested that the population structure was typical of species with widespread planktonic dispersal. Clearly, for $O$. mucosa, the vast majority of dispersal and genetic exchange occurs during the larval stage.

The second consequence of restricted gamete dispersal relates to the highly skewed sex ratios observed within rockpools. Within any rockpool, anemones tended to be either all male or all female, and this was particularly apparent for smaller rockpools containing a few individuals, where all appeared to be the same sex. In larger rockpools, males and females were often in small single-sex clumps, spatially separated from each other (D. Marshall pers. obs.). We believe that this marked bias in sex ratios within rockpools is a product 
of asexual reproduction, whereby a single recruit enters a rockpool and then asexually reproduces, with the clones retaining the original sex (Schick 1991). The clones may then be unable to move among different rockpools. Sebens (1981) anticipated this problem, and suggested that dense aggregations of single-sex groups of anemones may experience very low rates of fertilisation. This would mean that despite relatively high densities of conspecifics within rockpools, fertilisation success could still be relatively low.

The third consequence of restricted gamete dispersal is its effect on spawning synchrony. Within all-female pools, spawning synchrony depended on the proximity of the nearest rockpool containing a spawning male, with pools that were close to spawning males having higher synchrony. For a range of invertebrates (and anemones in particular), sperm has been shown to induce spawning in females (Clark \& Dewell 1974, Spaulding 1972, Sebens 1981, Pennington 1985, O'Connor \& Heasman 1995). Sperm or some associated product may act as a spawning trigger in Oulactis mucosa, with the effectiveness of this trigger degrading with dilution. Consequently, spawning synchrony within female pools would decrease sharply with increasing distance to the nearest spawning male, as observed in the present study. Interestingly, the likelihood of fertilisation success and spawning synchrony decreased over similar scales. Free-spawning invertebrates have been suggested to suffer from 'Allee' effects (Allee 1931), whereby decreases in the density of conspecifics result in lower reproductive success due to sperm limitation (Levitan 1995). We suggest that the problems associated with lower densities will be exacerbated by reductions in spawning synchrony, and that this represents a previously unrecognised, novel Allee effect. It should be noted that in other populations of $O$. mucosa, the majority of individuals live in small channels (Hunt \& Ayre 1989), and therefore may not encounter the same restricted dispersal of gametes.

Many anemone species display particularly low rates of recruitment from sexual reproduction (Schick 1991, Perrin et al. 1999). In the present study, less than half $(42 \%)$ of the spawned eggs were fertilised on average. This is similar to the number reported for another freespawning intertidal invertebrate (Pyura stolonifera, mean fertilisation success $\approx 45 \%$ : Marshall 2002), but is well above the values predicted for gametes spawned directly into the surf zone (Denny \& Shibata 1989). Whilst the fertilisation rates we observed were relatively low, a good proportion of eggs were still fertilised, and it seems unlikely that fertilisation is the limiting factor in the recruitment of Oulactis mucosa.

To summarise, despite spawning relatively asynchronously in a potentially harsh habitat, Oulactis mucosa achieves moderate fertilisation success by spawning gametes in a viscous matrix during low tide. Gamete dispersal among rockpools appeared to be highly limited, and spawning synchrony within rockpools strongly related to the proximity of rockpools containing spawning males, suggesting only a limited 'communication' among rockpools. Female fertilisation success was strongly related to the presence of spawning males within the rockpool, and gamete residence times appeared to be relatively short (the duration of the low tide). The fertilisation success of isolated females was extremely low, and was presumably limited by the availability of sperm. It seems that fertilisation success in this species is highly variable, and is likely to depend strongly on local population densities. Spawning at low tide may avoid the problem of sperm dilution, but it restricts sperm transport among rockpools and, given the skewed sex ratios within rockpools, fertilisation success will be extremely variable. Overall, our confidence in the results reported herein is qualified by the fact that this study examined a relatively small number of individuals. Ideally, data from repeated spawnings should be compiled to give a more complete picture of the fertilisation ecology of this species. However, given the extreme difficulty of predicting the occurrence of these spawnings, coupled with the relatively short duration of the actual spawning event, the possibility of conducting repeated observations is extremely unlikely. Consequently the data presented herein comprise the best estimate of fertilisation success for this species to date.

Acknowledgements. We wish to thank P. \& B. Semmens for providing accommodation, David Ayre and Mick Keough for very helpful advice and 2 anonymous reviewers for comments that greatly improved the manuscript.

\section{LITERATURE CITED}

Allee WC (1931) Animal aggregations: a study in general sociology. University of Chicago Press, Chicago

Ayre DJ (1988) Evidence for genetic determination of sex in Actinia tenebrosa. J Exp Mar Biol Ecol 116:23-34

Berndt ML, Callow JA, Brawley SH (2002) Gamete concentrations and timing and success of fertilization in a rocky shore seaweed. Mar Ecol Prog Ser 226:273-285

Billingham MR, Ayre DJ (1997) Asexual reproduction and genetic determination of colour patterns within populations of the subtidal sea anemone Anthothoe albocincta. Mar Ecol Prog Ser 156:121-130

Brawley SH (1992) Fertilisation in natural populations of the dioecious brown alga Fucus ceranoides and the importance of the polyspermy block. Mar Biol 113:145-157

Brawley SH, Johnson LE, Pearson G, Speransky V, Li R, Serrao EA (1999) Gamete release at low tide in fucoid algae: maladaptive or advantageous? Am Zool 39:218-231

Chia FS (1976) Sea anemone reproduction: patterns and adaptive radiations. In: Mackie GO (ed) Coelenterate ecology and behaviour. Plenum Press, New York, p 261-270 
Clareboudt M (1999) Fertilization success in spatially distributed populations of benthic free-spawners: a simulation model. Ecol Model 121:221-233

Clark WH, Dewell WC (1974) The structure of the gonads, gametogenesis, and sperm-egg interactions in the Anthozoa. Am Zool 14:495-510

Denny M, Dairiki J, Distefano S (1994) Biological consequences of topography on wave-swept rocky shores. I. Enhancement of external fertilization. Biol Bull (Woods Hole) 183:220-232

Denny MW, Shibata MF (1989) Consequences of surf-zone turbulence for settlement and fertilization. Am Nat 134: 859-889

Denny MW, Nelson EK, Mead KS (2002) Revised estimates of the effects of turbulence on fertilization success in purple sea urchin, Strongylocentrotus purpuratus. Biol Bull (Woods Hole) 203:275-277

Edmands S (1995) Mating systems in the sea anemone genus Epiactis. Mar Biol 123:723-733

Franke ES, Babcock RC, Styan CA (2003) Sexual conflict and polyspermy under sperm-limited conditions: in situ evidence from field simulations with the free-spawning marine echinoid Evechinus chloroticus. Am Nat 160: 485-496

Havenhand JN (1991) Fertilisation and the potential for dispersal of gametes and larvae in the solitary ascidian Acidia mentula Müller. Ophelia 33:1-15

Hunt A, Ayre DJ (1989) Population structure in the sexually reproducing sea anemone Oulactis mucosa. Mar Biol 102: $537-544$

Levitan (1988) Asynchronous spawning and aggregative behaviour in the sea urchin Diadema antillarum Phillipi. In: Burke R (ed) Echinoderm biology. Proc 6th Int Echinoderm Conf. Balkema Press, Rotterdam, p 1-6

Levitan DR (1993) The importance of sperm limitation to the evolution of egg size in marine invertebrates. Am Nat 141: $517-536$

Levitan DR (1995) The ecology of fertilization in freespawning invertebrates. In: McEdward L (ed) Ecology of marine invertebrate larvae. CRC Press, Boca Raton, FL, p 125-152

Levitan DR (2000) Density dependent selection on gamete traits in three congeneric sea-urchins. Ecology 82:464-479

Levitan DR, Petersen C (1995) Sperm limitation in the sea. Trends Ecol Evol 10L:228-231

Marshall DJ (2002) In situ measures of spawning synchrony and fertilization success in an intertidal, free-spawning invertebrate. Mar Ecol Prog Ser 236:113-119

McEuen FS (1988) Spawning behaviours of northeast Pacific sea cucumbers (Holothuroidea: Echinodermata). Mar Biol 98:565-585

Mead KS, Denny MW (1995) The effect of hydrodynamic shear stress on fertilization and early development of the purple sea urchin Strongylocentrotus purpuratus. Biol Bull (Woods Hole) 188:46-56

Meidel SK, Yund PO (2001) Egg longevity and time-integrated fertilization in a temperate sea urchin (Strongylocentrotus droebachiensis). Biol Bull (Woods Hole) 201: $84-94$

O'Connor WA, Heasman MP (1995) Spawning induction and fertilisation in the doughboy scallop Chlamys (Mimachalmys) asperrima. Aquaculture 136:117-129

Pennington JT (1985) The ecology of fertilization of echinoid eggs: the consequences of sperm dilution, adult aggrega-

Editorial responsibility: Roger Hughes (Contributing Editor), Bangor, UK tion and synchronous spawning. Biol Bull (Woods Hole) 169:417-430

Perrin MC, Thorpe JP, Sole-Cava AM (1999) Population structuring, gene dispersal and reproduction in the Actinia equina species group. Annu Rev Oceanogr Mar Biol 37: $129-152$

Schick JM (1976) Ecological physiology and genetics of a colonizing actinian Haliplanella luciae. In: Mackie GO (ed) Coelenterate ecology and behaviour. Plenum Press, New York, p 137-146

Schick JM (1991) A functional biology of sea anemones. Chapman \& Hall, London

Schick JM, Lamb AN (1977) Asexual reproduction and genetic population structure in the colonizing sea anemone Haliplanella luciae. Biol Bull (Woods Hole) 153: 604-617

Sebens KP (1981) Reproductive ecology of the intertidal sea anemones Anthopleura xanthogrammica (Brandt) and A. elegantissima (Brandt): body size, habitat and sexual reproduction. J Exp Mar Biol Ecol 54:225-250

Serrao EA, Pearson G, Kautsky L, Brawley SH (1996) Successful external fertilization in turbulent environments. Proc Natl Acad Sci USA 93:5286-5290

Siebert AE (1974) A description of the embryology, larval development, and feeding of the sea anemones Anthopleura elegantissima and A. xanthogrammica. Can J Zool 52:1383-1388

Spaulding JG (1972) The life cycle of Peachia quinquecapitata, an anemone parasitic on medusae during its larval development. Biol Bull (Woods Hole) 143:440-453

Speransky SR, Brawley SH, Halteman WA (2000) Gamete release is increased by calm conditions in the coenocytic green alga Bryopsis (Chlorophyta). J Phycol 36:730-739

Strathmann MF (1991) Phylum Cnidaria, Class Anthozoa. In: Strathmann MF (ed) Reproduction and development of marine invertebrates of the northern pacific coast. University of Washington Press, Seattle, p 83-104

Styan CA, Butler AJ (2003) Asynchronous patterns of reproduction for the sympatric scallops Chlamys bifrons and Clamys asperrima (Bivalvia: Pectinidae) in South Australia. Mar Freshw Res 54:77-86

Temkin MH (1996) Comparative fertilization biology of gymnolaemate bryozoans. Mar Biol 127:329-339

Thomas FIM (1994a) Physical properties of gametes in three sea-urchin species. J Exp Biol 194:262-284

Thomas FIM (1994b) Transport and mixing of gametes in three free-spawning polychaete annelids Phragmatopoma californica (Fewkes), Sabellaria cementarium (Moore), and Schizobranchia insignis Bush. J Exp Mar Biol Ecol 179:11-27

Thorson G (1950) Reproduction and larval ecology of marine bottom invertebrates. Biol Rev 25:1-45

Williams ME, Bentley MG, Hardege JD (1997) Assessment of field fertilization success in the infaunal polychaete Arenicola marina (L.). Invertebr Reprod Dev 31:189-197

Yund PO (2000) How severe is sperm limitation in natural populations of marine free-spawners? Trends Ecol Evol 15: 10-13

Yund PO, McCartney MA (1994) Male reproductive success in sessile invertebrates-competition for fertilizations. Ecology 75:2151-2167

Yund PO, Meidel SK (2003) Sea urchin spawning in benthic boundary layers: are eggs fertilized before advecting away from females? Limnol Oceanogr 48:795-801

Submitted: July 4, 2003; Accepted: September 30, 2003

Proofs received from author(s): January 26, 2004 